Archived version from NCDOCKS Institutional Repository http://libres.uncg.edu/ir/asu/

\title{
Appalachỉan
}

B O O N E, N O R T H C A R O L I N A

\section{Baby And Me: Single Mothers By Choice And The Artificial Reproductive Technology Marketplace}

\author{
By: Sarita Ray Chaudhury and Pia A. Albinsson
}

\begin{abstract}
This study adopts an interpretive research approach to explore the consumer experiences of a self-identified group, "Single Mothers by Choice" (SMCs). These women are either in the process of becoming mothers, or have attained motherhood, with the help of the assisted reproductive technologies (ART) industry. In the mid-nineties, the fledgling ART industry sought to serve heterosexual couples in (preferably) long-term committed relationships that faced problems in conceiving naturally (Houston, 2004). A decade later, the profit seeking industry's rapid embrace of "other mothers," (single and lesbian women) is indicative of an evolving marketplace that is largely unregulated and may be selective of who it serves (Houston, 2004). The potential vulnerabilities of such a marketplace invite further exploration by consumer researchers. Research on motherhood indicates that this lifestage experience involves extensive transitional consumption as women undergo the physical and socio-cultural transformation into becoming mothers. Recent research on new mothers' consumer experiences (Jennings and O'Malley, 2003; Prothero, 2002; Carrigan and Sczmigin, 2004; Thomsen and Sorensen, 2006; Banister and Hogg, 2006; Voice Group, 2010) challenge dominant theoretical assumptions that consumers are automatically motivated to make informed decisions to consume through transitory life-roles (Voice Group, 2010). In this research we seek to understand the lived experiences of SMCs as they attain motherhood through ART.
\end{abstract}

Chaudhury S.R., Albinsson P.A. (2016) Baby and Me: Single Mothers by Choice and the Artificial Reproductive Technology Marketplace. In: Plangger K. (eds) Thriving in a New World Economy. Developments in Marketing Science: Proceedings of the Academy of Marketing Science. Springer, Cham. Publisher version of record available at: https://link.springer.com/chapter/10.1007/978-3-319-24148-7_56 


\title{
BABY AND ME: SINGLE MOTHERS BY CHOICE AND THE ARTIFICIAL REPRODUCTIVE TECHNOLOGY MARKETPLACE
}

\author{
Sarita Ray Chaudhury, Humbolt State University, USA \\ Pia A. Albinsson, Appalachian State University, USA
}

This study adopts an interpretive research approach to explore the consumer experiences of a self-identified group, "Single Mothers by Choice" (SMCs). These women are either in the process of becoming mothers, or have attained motherhood, with the help of the assisted reproductive technologies (ART) industry. In the mid-nineties, the fledgling ART industry sought to serve heterosexual couples in (preferably) long-term committed relationships that faced problems in conceiving naturally (Houston, 2004). A decade later, the profit seeking industry's rapid embrace of "other mothers," (single and lesbian women) is indicative of an evolving marketplace that is largely unregulated and may be selective of who it serves (Houston, 2004). The potential vulnerabilities of such a marketplace invite further exploration by consumer researchers. Research on motherhood indicates that this life-stage experience involves extensive transitional consumption as women undergo the physical and socio-cultural transformation into becoming mothers. Recent research on new mothers' consumer experiences (Jennings and O'Malley, 2003; Prothero, 2002; Carrigan and Sczmigin, 2004; Thomsen and Sorensen, 2006; Banister and Hogg, 2006; Voice Group, 2010) challenge dominant theoretical assumptions that consumers are automatically motivated to make informed decisions to consume through transitory life-roles (Voice Group, 2010). In this research we seek to understand the lived experiences of SMCs as they attain motherhood through ART.

The first phase of our study consisted of netnographic discourse analysis (Kozinets, 2010) of posts and blogs from select online communities of self-identified SMCs to understand and contextualize their consumption experiences in the ART marketplace. In the second phase of the study we recruited eighteen informants to participate in e-mail and Skype interviews (Ballantine and Creery, 2010). Since we aimed to understand overall consumer experiences in the ART marketplace, we included SMCs who traversed the entire gamut of the motherhood experience. We invited our participants to narrate their life-stories of how they initially decided to become a parent. Interview topics ranged from their reproductive background, romantic relationships, kin and social networks, careers and finances, and ideas about motherhood and family.

SMCs exchanged surprisingly candid technical, financial, and medical information in their online discourses. Preliminary findings from data analysis through iterative readings conducted independently by the two authors revealed that many SMCs described receiving positive reception as prospective customers at the ART clinics. However, social exclusion and fear of disapproval from social and kin networks were prominent in these discussions as were signs of defiance and celebration of independent decisions within virtual SMC communities. Womens' consumption experiences in the ART industry, which due to its position as unregulated and largely unaccountable to customers, has been known to differentially treat single women (straight or lesbian) and heterosexual, married couples (Houston, 2004). In addition, our data analysis include accounts of treatment misinformation, inadequate screening processes of sperm donors, and deliberate withholding of financial obligations indicate a discernible lack of consumer control in a life event fraught with emotional investment in the consumption process. Our findings show that conceiving through ART is the least desirable choice for all women irrespective of their single or married status. 'Trying to make a baby' through the conventional route of love, marriage and sex, is portrayed as a positive experience of welcoming a child into the world to a two parent loving family. It is a powerful narrative that is ingrained in the cultural fabric of most societies. ART is often the last, desperate effort to experience pregnancy and biological motherhood for many women (Hertz, 2006). Previous research has indicated that heterosexual couples who resort to ART due to infertility problems draw strength and support from each other as they experience the emotionally and physically strenuous journey to parenthood (Fischer, Otnes and Tuncay, 2007). SMCs on the other hand report loneliness as they contemplate becoming single mothers through ART with the added burden of secrecy for fear of disapproval and exclusion from social networks (Hertz, 2006).

In conclusion, our research extends previous research on motherhood related consumer experiences (Fisher, Tuncay and Otnes, 2007; Houston, 2004) by developing a conceptual model that describes the transitional life-stage of SMCs and their interactions with the ART marketplace. The model outlines individual and collective resources of SMCs and other influences that contest and shape their experiences as ART consumers. The model illustrates how the advent of scientific technology, combined with fading boundaries of the digital and physical world of human social networks, influence evolving consumer experiences of women who choose to become mothers without the direct help of Mother Nature.

References Available Upon Request. 